\title{
Engaging Schools in the Science of Low-Energy Buildings
}

\author{
Fiona Charnley, Paul Fleming, Tony Dowsett, Margaret Fleming*, Malcolm \\ Cook**, Greig Mill \\ Institute of Energy and Sustainable Development, De Montfort University, Leicester, UK \\ * MF Associates, Leicester, UK \\ ** Loughborough University, Loughborough, UK
}

Email Corresponding Author: fcharnley@dmu.ac.uk

This paper explores the relationship between the previous government's initiative to rebuild and renew secondary schools in the UK, and the requirement for improved education for sustainable development. The documented research utilised a number of mechanisms to engage with pupils in Leicester City schools to increase their awareness, knowledge and understanding of the science and engineering associated with the design and operation of low-energy school buildings. Workshops, discussions with energy and sustainable development experts and inspirational visits to existing low-energy buildings were utilised to develop an appreciation for the importance of energy efficiency and best design practice. The results demonstrate an increase in pupil's knowledge and understanding of low-energy school design and additionally a rise in those pupils who are interested in science and would consider it as a career option.

\section{Introduction}

The World Summit on Sustainable Development (WSSD, 2002) and the Sustainable Development Action Plan 'Brighter Futures - Greener Lives' issued by the Department for Children, Schools and Families (DCSF, 2008) both argue for a population that is educated to understand sustainable development. This is a challenge that some schools were in a unique 
position to meet due to the 'Building Schools for the Future' initiative. Building schools for the Future (BSF) was a national initiative which aimed to use building design to support $21^{\text {st }}$ century education (Teachernet, 2009). The aim to increase standards of education was coupled with the opportunity to greatly reduce energy use, by developing carbon neutral schools.

The project; 'Engaging pupils, teachers and governors in the science, engineering and technology of carbon 'neutral' schools', embraced the opportunity that BSF provided and strengthened the link between education for sustainable development (ESD) and the design and construction of new school buildings. Additionally, through the use of the sustainable development of school buildings, the research aimed to increase pupil's interest in science and engineering. Researchers engaged with four schools in Leicester City that were within Phase One of the BSF process. Experts from the Institute of Energy and Sustainable Development at De Montfort University, facilitated multiple engagement events for pupils, teachers and Governors of the schools to increase their knowledge and understanding of issues surrounding climate change, and the science and engineering associated with low energy school buildings. The project resulted in a number of discussions between school pupils, designers, architects and policy makers in which pupils expressed their requirements for a more energy efficient school, using sophisticated terminology and complex design ideas. These ideas included the need to reduce energy demand across the school, the wish for more natural day lighting, the acknowledgement of site orientation for the maximisation of solar gain and the aspiration for renewable technologies for use within lessons. The paper demonstrates how engagement mechanisms were successfully employed and resulted in an increase in the knowledge and understanding of the sustainable development of low-energy school buildings. 


\section{Research Context}

The great bulk of current UK schools were designed either in the late nineteenth century by the Victorians, or in the post-war years of 1945 - 1975. Many Victorian schools lack essential features and are in need of major and costly repair, and additionally, those built in the post-war era have been severely criticised for failing to function effectively (Bentley et al., 2001). Subsequently, the BSF initiative was long overdue and had the potential to re-structure not only buildings for future learning and teaching but also to substantially improve the quality of that education. The programme was a key part of the previous government's agenda for education reform (Teachernet, 2007) and subsequently it was suggested that the key driver and measure of its success would be the impact that the new schools have on teaching and learning transformation and how they contribute to an improved standard of education (LMEC, 2008). The positive impact that well designed school buildings and environments have on their occupants everyday lives and wellbeing has been well researched (Olson and Kellum, 2003, Vaughan, 2009). Additionally, authors suggest that well designed school buildings and environments can have a positive impact on attendance, behaviour and academic achievement (Durán-Narucki, 2008). In terms of the built environment, for instance, environmental psychologists have found that factors such as acoustics, air quality, light levels, noise levels and temperature all have measurable effects on individual performance by varying individuals' levels of attention and alertness, concentration and effectiveness (Bentley et al., 2001).

There is a concern, however, that despite the wealth of design talent in the UK, we do not currently have the expertise required to design these innovative, sustainable and inspirational environments. Bentley et al., (2001) reported that out of the 7 designers working on their school design project 'not one had worked directly with schools before and hardly any could name a 
professional that had'. They concluded that if designers have no sense of the outcomes that the educational system is striving to deliver, or of the social and organisational characteristics of school life, then it is difficult to see how they can design with these factors in mind.

The engagement and participation of pupils and teachers has been identified as one solution to this concern. The House of Commons report, surrounding the BSF initiative, suggested that the early engagement of the whole school community is an important part of the development process. They strongly encourage what is now common practice for key stakeholders, including school staff and pupils, to work collaboratively to develop a building brief (House of Commons report 2006/07). Literature suggests that engaging pupils in the development of their new schools should come hand in hand with education for sustainable development. Scott (2002) advises that we ought to want schools to help learners develop critical understandings of sustainable development, and help them achieve levels of critical environmental literacy that will enable them to develop and continually adapt their own understandings and make up their own minds as to how (and whether) to change the ways that they live. It would be more ethical, and more useful, were we to acknowledge that the purpose of education in relation to sustainable development was to explore the concept and its implications, tolerating different views in this process, rather than to persuade people to accept it, whatever its implications. A recent review of best practice concerning schools engagement with sustainability has been conducted by Symons (2008). The report suggests that those schools which have embedded sustainability report a range of positive outcomes including higher levels of attainment or 'value-added progress' (Jackson, 2007), a motivator of enthusiasm and interest (Symons, 2008) and many found that ESD provided a useful vehicle for organizing and coordinating aspects of Every Child Matters (Ofsted, 2008). However currently it appears that young people's knowledge of natural resources and the environment can be patchy, mediated more through television than first hand experience. Additionally, although The National Curriculum has, for many years, included specific references 
to sustainable development there is limited literature surrounding the success of ESD and additionally, based on the findings from the $1^{\text {st }}$ BSF phase, there is substantial room for improvement (DSCF, 2008). Ofsted (2008) stated that most of the schools utilised within their study had limited knowledge of sustainability and work in this area tended to be uncoordinated, often confined to special events rather than being an integral part of the curriculum. Consequently they recommended that:

- sustainable development should be linked more closely to building schools for the future,

- schools should integrate sustainable development into their development plans,

- all pupils should be given the opportunity to learn about, and take an active part in, promoting sustainability within the school and beyond, through membership of school councils, eco councils and other groups.

Additionally, the Ofsted report suggests that pupils should not only have substantial knowledge surrounding sustainable development but that 'they should develop the ability to discuss and debate issues at a sophisticated level, presenting well argued opinions and considering the views of others'. Subsequently it appears that involving pupils in the design process is necessary, not only for the education of future generations, but additionally to provide designers with invaluable insight and guidance surrounding the requirements of a new school building. 


\section{Engaging young people in the development of low-energy schools}

Having identified the need to involve young people in the development of their new schools, discussion now needs to concern ways in which this can best be achieved. Work has been undertaken on the link between educational programmes and changing the attitudes of pupils towards environmental problems (Devine-Wright et al. 2004). One major concern surrounding education is that many pupils are no longer finding scientific subjects interesting. It is suggested that although there is great potential, school science fails to convey the extent to which science is related to everyday life and affects all of us (Planet science, 2003). The National Curriculum states that real-world applications of science are an important part of the brief to enrich students'

curriculum experience. Science is not restricted to the laboratory, but is highly relevant to life outside school and the world of work in particular, (National Curriculum in Action website, 2009). Space needs to be made to allow controversial issues to be included and to allow topics to be studied in more depth, (Planet Science, 2003).

The majority of individuals do not believe that they are responsible for or can engage in any actions that will be environmentally efficacious (Uzzell, 2000). Consequently, removing pupils from their common learning environment to expose them to ways in which climate change and environmental issues are directly affecting them and their own communities may be a way of raising environmental awareness. Scott (2002) agrees suggesting that institutions such as schools need to be free to take up and explore with learners what sustainable development might be in ways that make contingent and contextual sense.

Scott goes on to describe four kinds of responsibilities that educators have to learners regarding education for sustainable development: 
1) to help learners understand why the idea of sustainable development ought to be of interest to them

2) to help learners gain plural perspectives on issues from a range of cultural stances

3) to provide opportunities for an active consideration of issues through appropriate pedagogies which, for example, might begin from learner's and teacher's different interests, helping pupils to understand what they are learning and its significance

4) to encourage pupils to continue to think about what to do, individually and socially, and to keep their own and other people's options open.

The Department for Children, Schools and Families (DCSF) agree, stating that in addition to our own actions to improve our sustainability, we need to empower young people with the skills, knowledge and freedom to voice their opinions and to make a difference (DCSF, 2008). Therefore, educating and empowering them to make their own decisions and communicate these to appropriate decision makers and designers within the context of low-energy schools is a promising way to achieve this. It is important to stimulate without prescribing and to encourage pupils to see conceptual frameworks as scaffolding to build learning around, rather than as barriers to new ideas, (Scott, 2002).

\section{Method}

The literature presented has provided evidence that engaging pupils in the development of their new school buildings is a promising method of ensuring good school design and subsequently better standards of learning and teaching for the future. This literature has therefore informed the current study and resulted in the following aims: 
1) To engage pupils, teachers and governors in the science and engineering of a low-energy school,

2) To facilitate an increase in awareness, knowledge and understanding of climate change and low-energy building design using current research and best practise building design principles,

3) To enable discussions to be held between pupils, designers and policy makers to provide pupils with the opportunity to influence the design of their new school buildings.

Due to the complexity surrounding the area of sustainable development and low-energy building design various methods were selected to communicate and engage with the pupils. Johnson et al., (1981) suggested that when individuals encourage and teach one another and use cooperative structures, they have a tendency to promote greater performance than in more competitive or individualistic ones. Subsequently, collaborative learning was implemented in the form of workshops and discussions, as opposed to individual assignments and examinations. The Department for Education and Skills (DfES) advised that sustainable development offers a reallife context that can make learning more meaningful and relevant. It can enhance pupils' enjoyment and progress, and build practical life skills (DfES, 2006). For this reason engagement events utilised real-life contexts as much as possible including the facilitation of visits to existing low-energy buildings to enable pupils to visualise energy efficiency more effectively.

In total 102 pupils from 4 secondary schools took part in the engagement events and were aged between 10 and 14 years old. Pupils were selected as they were already part of the school's Eco-management and Audit Scheme (EMAS) or else they were members of the school council. The engagement events were developed and facilitated by researchers from De Montfort 
University, Leicester in collaboration with an educational consultant and teachers from the schools. This ensured that the study fitted in with current educational practice and the National Curriculum.

\subsection{Engagement Events}

A number of engagement activities took place over the course of the project which involved pupils, teachers and governors from each of the schools involved. These activities are now detailed:

Inspirational Visit: Pupils and teachers were taken on a tour of an existing low-energy building. The tour was facilitated by an expert in low-energy building design and aspects such as thermal insulation, natural ventilation, acoustics, construction and the use of natural day lighting were pointed out and discussed. The building design expert also explained the design and operation of the building. The inspirational visit allowed pupils and teachers to visualise what was possible in their own school whilst getting a good understanding of low-energy building design within a real life context.

Sustainability Workshop: a day long sustainability workshop was held for teachers and pupils. Experts within the field introduced participants to issues surrounding climate change, the need for more sustainable development and the design principles behind the development of a low-energy building. Multiple techniques were used during the workshop to capture the participant's attention and to communicate the complex information in an exciting and inspiring way. These included the use of multi-media presentations, group exercises and the use of on-line games. Resources for the workshop were developed for the project in partnership with the Centre for Alternative Technology to enable pupils to fully understand the complex science and engineering issues surrounding the design of low-energy school buildings.

Architecture Week: To coincide with National Architecture Week, pupils from each of the four schools attended an engagement event with architects. This consisted of architects and 
building designers working over a two-day period with pupils from each of the four schools. Pupils were able to build on the knowledge they had gained from the previous engagement events and hold informed discussions surrounding the design of their new schools. Pupils prepared a short presentation on their findings and debated these requirements with the consortia.

Presentation to the Design Team: As part of the BSF development process the design team engaged with each school surrounding their requirements for the new school. Pupils again made short presentations to architects and building designers. They showed images of examples of sustainable schools and argued for why "sustainability" should be included in their new school design.

Discussion with Policy Makers: Researchers held meetings with DfES officials, the British Council for School Environment, WWF and head teachers and pupils from other low energy schools in the UK. The meetings centred on education for sustainable development in UK schools. Mechanisms for engaging all building users in the sustainable operation of school buildings were also explored. The policy makers were particularly interested in leadership issues and how to monitor and evaluate energy and water consumption reductions in school buildings.

Governors Day: Discussions between Governors, researchers and the BSF design team took place. Debate with Governors on the advantages and disadvantages of a "sustainable school" resulted in the schools involved requesting a design that moved towards a "carbon neutral" school.

\subsection{Data Collection and Analysis}

To enable any increase in knowledge and understanding to be measured, surveys were conducted with the pupils prior to and after the engagement activities. Questions around climate change within the survey were developed in correspondence to those used in the DEFRA 'Attitudes to climate change amongst young people' surveys (2006 and 2008). This was done to ensure that a 
comparison between these results and the national results could be made. Additionally all questions used within the survey were trialled beforehand to ensure validity and aptness.

Qualitative data was also collected during the engagement events. Researchers held discussions with the participants during which open ended questions were asked. Opinions surrounding climate change and low-energy building design were captured using digital voice recorders, discussions with experts also captured aspects that the participants were not clear of.

Additionally, participants were asked more structured questions surrounding the engagement events themselves. All qualitative data was transcribed and analysed. The following section presents the findings from the study.

\section{Findings}

The project was successful in directly engaging 102 pupils in the science and engineering of lowenergy school buildings. This was done through the use of multiple engagement techniques and activities. The reasons for engaging pupils in this way was to facilitate an increase in knowledge and understanding of low-energy building design so that pupils were able to participate in informed discussions with experts to influence the design of their schools. This section details how these aims were achieved.

\subsection{Facilitating an increase in awareness, knowledge and understanding of climate change and low-energy building design}

From the data it was possible to identify an increase in the knowledge, awareness and understanding of the science and engineering associated with the development of low-energy school buildings. 
There was a significant increase in pupil awareness surrounding phrases associated with sustainable development and additionally places in which they had heard the phases. The most common phrases that pupils had heard of, following the engagement activities, were 'Renewable Energy' which increased from $86 \%$ to $100 \%$ and 'Climate Change' which increased from $81 \%$ to $100 \%$. There was also a substantial increase in pupils who had heard of the terms 'Energy Efficiency', 'Sustainable Development', 'Global Warming' and 'The Green House Effect'.

An increase in the number of sources, from which the pupils had heard of the terms, also reflected a raised awareness surrounding the topic. At the end of the project, the pupils were hearing more about sustainability issues from wider sources of information. As expected, pupils showed a significant increase in hearing about the issues in school, which significantly rose from $81 \%$ to $94 \%$. However, it was reported that newspapers, radio and friends were also increasingly discussing issues of sustainable development. This could also be due to the fact that as the pupils became more aware of the terms and meanings, they took notice when such issues were being talked about. The pupils found that they heard more about sustainability and energy efficiency issues from their friends than other social groups. This is encouraging as within the study it was also identified that 'friends' tend to be the social group that have the most influence over behaviour. Surprisingly results suggested that the number of pupils who were discussing these issues at home decreased from $67 \%$ prior to the engagement events to $59 \%$ after the events. This could possibly be due to the focus of the events being around the school buildings. Future work needs to ensure that pupils are encouraged to discuss the knowledge they have gained at home and additionally the content of the events should include measures that pupils can take at home to reduce energy consumption as well as in school. 


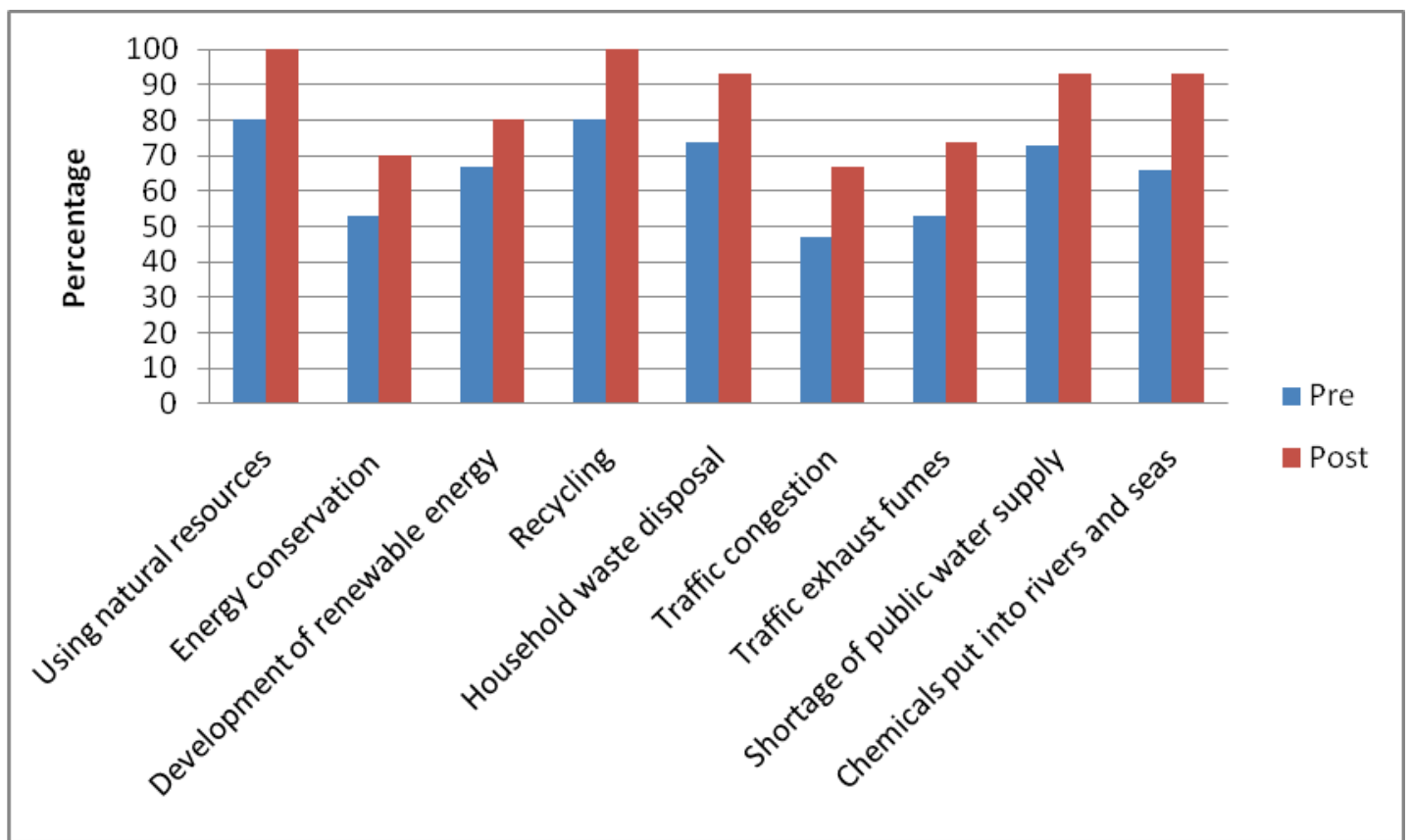

Figure 1: Percentage of pupils who responded positively to the question: How concerned are you about these specific issues?

Findings from the study also suggest that, following the engagement events, pupils demonstrated a higher level of concern for the environment. Pupils were asked the question 'How concerned are you about these specific issues?' and were given the options 'very concerned', 'fairly concerned', 'not very concerned', 'not at all concerned' and 'I don't know'. Figure 1 represents the percentages of pupils that answered positively (very and fairly concerned) both before and after the engagement events. As shown, pupils' level of concerns increased after the engagement activities in all areas. Two of the lowest percentages of concern were observed in 'traffic congestion' and 'traffic exhaust fumes'. This was possibly due to the fact that the engagement events tended to focus on the development of new school buildings and so emissions from vehicles may not have been emphasised as much as 'the use of natural resources' for example. When addressing the carbon footprint of a 'sustainable' school' it is often debated as to whether emissions from vehicles coming to and from the school should be included. However, the National Framework for Sustainable Schools (2009) suggests that 'travel and traffic' should be part of a whole management approach to a more sustainable school. By 2020 the government 
would like all schools to be models of sustainable travel where vehicles are used only when absolutely necessary and facilities for healthier, less polluting or less dangerous modes of transport are exemplary (The National Framework for Sustainable Schools, 2009). Subsequently it is essential that traffic and travel is included in education for sustainable development.

The study also found that pupils became more aware of the impact that they themselves could have on the effects of climate change. $88 \%$ of the pupils thought that they could make a contribution to reducing the effects of climate change following the activities compared with $73 \%$ prior to the activities.

Figure 2 shows the responses to the question 'Which of the following have a responsibility for conserving energy'. The baseline survey reported that $80 \%$ of pupils thought that they themselves were responsible for conserving energy which was an encouraging initial response. This then increased to $88 \%$ following the engagement events. There was also an increase in pupils who thought that local communities were responsible for energy conservation (from $60 \%$ to $81 \%$ ). This is again encouraging as frequently it is easier to assign responsibility to higher bodies rather than accepting responsibility at a local level. 


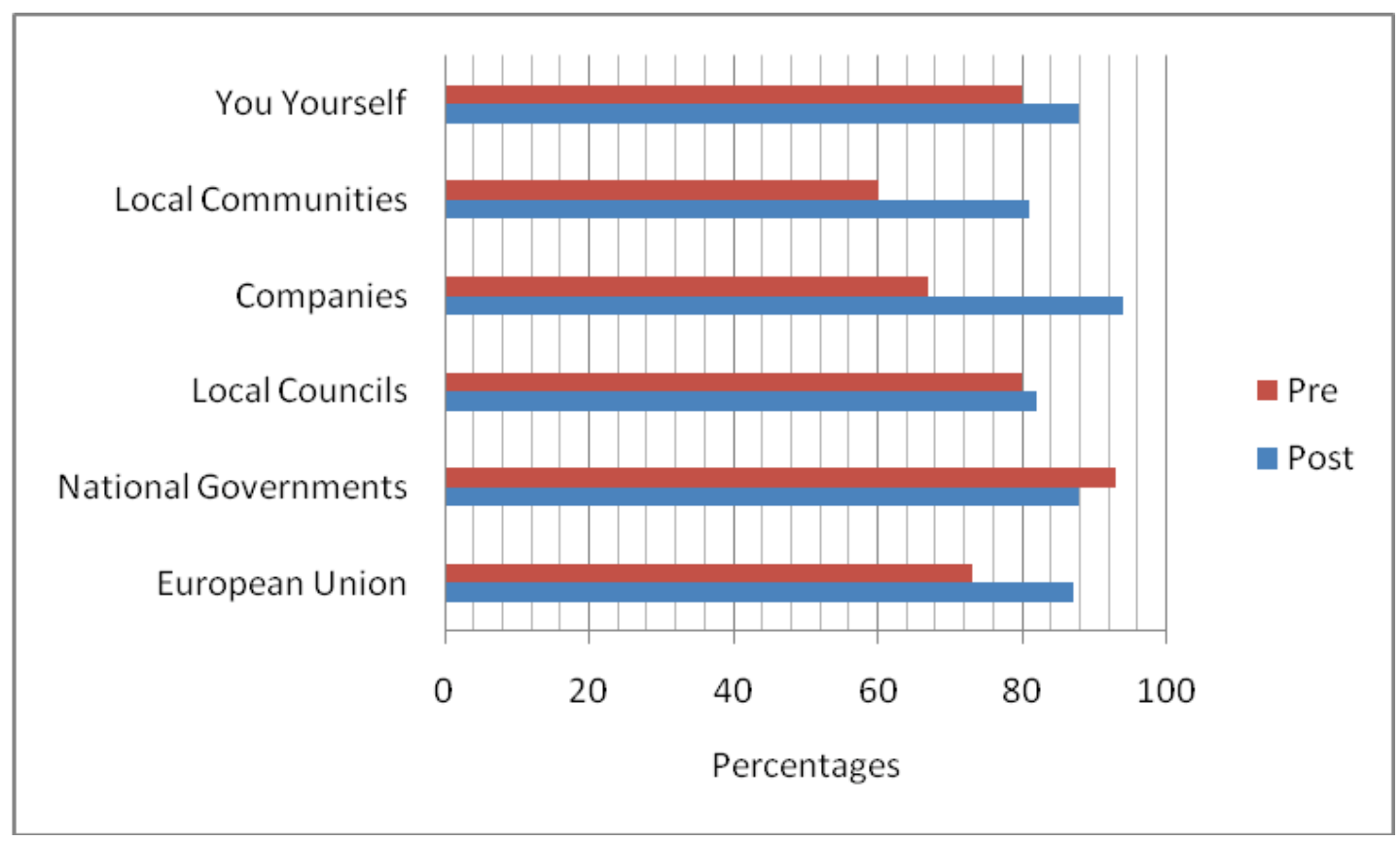

Figure 2: Percentage of pupils who answered 'yes' to the question: Which of the following have a responsibility for conserving energy?

As shown in figure 3, when asked 'Which of the following have a responsibility for using renewable energy' the percentage of pupils who deemed themselves as responsible was significantly smaller than responsibility for conserving energy. This may be because the young people perceived themselves as having little control over whether the buildings they used (e.g. school and home) were installed with renewable energy, where as energy conservation can be undertaken by anyone in any building. 


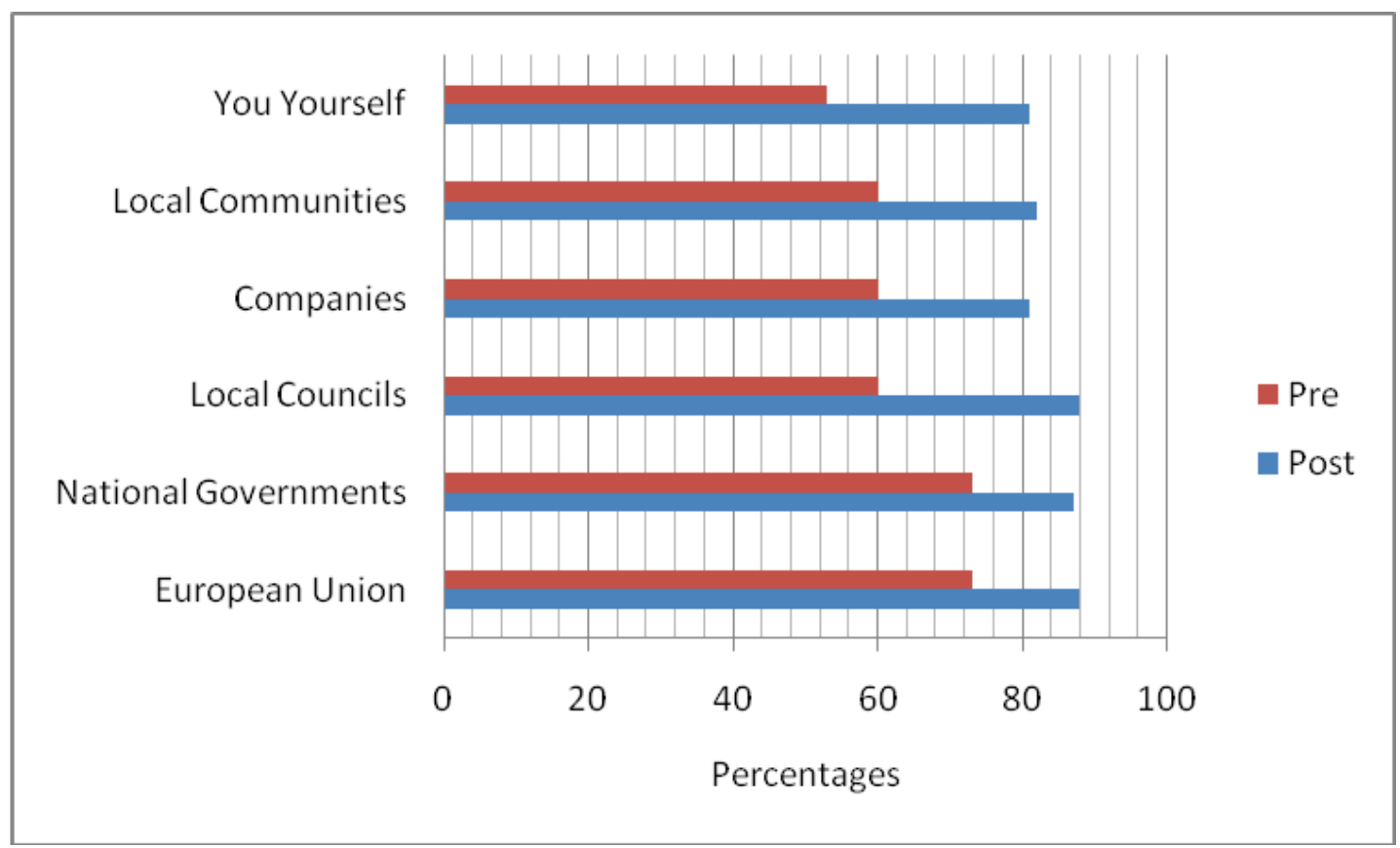

Figure 3: Percentage of pupils who answered 'yes' to the question: Which of the following have a responsibility for using renewable energy

When asked 'What are the major contributors to climate change?' the pupils produced various responses to the options provided. The baseline survey revealed that the three most prominent contributors were thought to be 'the destruction of forests' $(80 \%)$, 'the use of gas and electricity in industry' (73\%), and 'carbon dioxide emissions' (67\%). These were joined by several other factors in the follow-up survey which indicated that the pupils also recognised these factors as prominent contributors. The hole in the ozone layer became the third most popular contributor after the engagement events. The pupils found it difficult to distinguish between the causes of the hole in the ozone layer and the causes of climate change. This is understandable as both are caused by the emission of gases into the atmosphere. However, education for sustainable development must clarify that the hole in the ozone layer doesn't actually contribute to climate change. 


\begin{tabular}{|l|l|l|l|l|l|l|}
\hline Which of the following are major contributors to Climate Change? & Pre Yes & $\begin{array}{l}\text { Post } \\
\text { Yes }\end{array}$ & Pre No & Post No & $\begin{array}{l}\text { Pre } \\
\text { Don't } \\
\text { Know }\end{array}$ & $\begin{array}{l}\text { Post } \\
\text { Don't } \\
\text { know }\end{array}$ \\
\hline Carbon Dioxide Emissions & 67 & 71 & 20 & 0 & 13 & 29 \\
\hline Hole in the Ozone Layer & 60 & 79 & 20 & 0 & 20 & 21 \\
\hline Emissions from Power Stations & 47 & 64 & 20 & 7 & 33 & 26 \\
\hline Use of Gas / Electricity in Homes & 53 & 64 & 40 & 22 & 7 & 14 \\
\hline $\begin{array}{l}\text { Use of Gas / Electricity in } \\
\text { Industry }\end{array}$ & 73 & 86 & 7 & 0 & 20 & 14 \\
\hline Use of Mobile Phones & 13 & 14 & 74 & 57 & 13 & 29 \\
\hline Cars not using Unleaded Petrol & 54 & 43 & 33 & 14 & 13 & 43 \\
\hline Destruction of Forests & 80 & 86 & 0 & 0 & 20 & 14 \\
\hline Organic Farming & 20 & 21 & 53 & 43 & 27 & 36 \\
\hline
\end{tabular}

Table 1: Pupil responses to the question: Which of the following are major contributors to climate change?

When asked how confident they were that the earth's climate and long term weather patterns are changing, $88 \%$ of the pupils answered that they were very or fairly confident. This is a considerable increase from pre activity answers in which $73 \%$ of pupils were confident.

Not only was there an increase in awareness of sustainability issues and the outcomes of climate change, but pupils also addressed their own responsibilities towards these issues. Postengagement, $81 \%$ of pupils thought that human activity was the major cause of climate change, compared to only $67 \%$ pre-engagement. Only a small percentage $(9 \%)$ did not think that human activity was the major cause of climate change, however post-engagement, this percentage fell to $0 \% .19 \%$ of pupils after the project did not know if human activity was the major cause of climate change, which dropped from $24 \%$ prior to the engagement activities.

Pupils demonstrated an increase in their understanding of the possible implications of climate change, as represented in figure 4 . When asked 'What things, if any, do you think will happen as a result of climate change?' the most popular answers were 'the average temperature will increase' (93\%), 'changes in weather patterns' $(87 \%)$ and 'sea level rise and coastal flooding' (86\%). Following the engagement events there was a significant increase in the 
percentage of all the responses with the exception of 'problems with long term survival of humans in the world' which decreased from $66 \%$ to $52 \%$. Given that the engagement events were intended to provide pupils with examples of how climate change can be reduced, through the use of sustainable development, this particular result does not appear to be concerning.

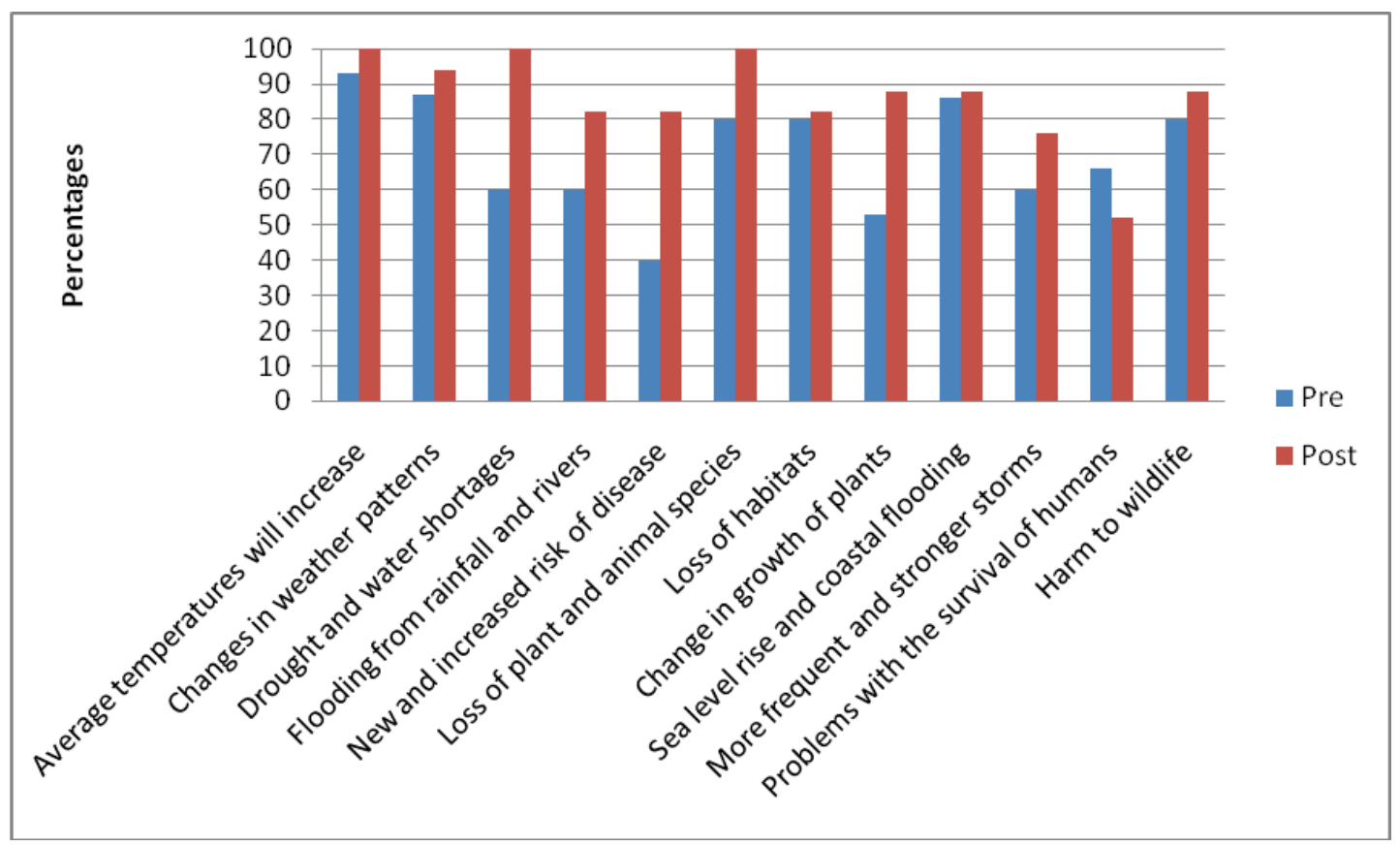

Figure 4: Percentage of pupils who answered 'yes' to the question: What things, if any, do you think will happen as a result of climate change

Data from the surveys, completed by the pupils both prior to and following the engagement events, showed an increase in pupils awareness, knowledge and understanding surrounding climate change. Additionally, the data also provided evidence that the pupils became more aware of their own behaviours and attitudes, and were able to identify ways in which they could help reduce the effects of climate change, thus being more responsible for their actions. In addition to this, qualitative data was collected during the engagement activities. This was captured through the work that the pupils had done; posters, presentations and 'wish lists' for their new schools, and also through discussions with pupils concerning what they had learnt from the project The following extracts were taken from the pupils responses: 
"You've got to look out for the environment" [Clare, 10],

"I know more about the environment now than before" [Ryan, 11],

"before I just used to think that pollution is mostly car pollution and that but in BSF you look deeper into it and find out new things" [Kieran, 13]

"it has made me think how we can do something to change the way we live" [Rhian, 14]

"I have become more aware through the BSF project about environmental issues" [Misha, 11]

“Understand more about sustainability and orientations and energy" [Tom, 14]

"I think the BSF has made me think more about environmental issues and all the stages" [Katie, 12]

There was also evidence that teachers had made a positive shift in their attitudes and knowledge, as shown in the following comment from one of the teachers that took part in the project:

"It has been good to know that others share the same opinions and feelings. I already had some knowledge on the subject, but I have learnt a lot more" 
Architects, designers, policy makers and councillors who took part in the discussions with pupils were very impressed with the high level of knowledge demonstrated. The pupils were able to answer their questions as the next section confirms.

\subsection{Facilitating discussions between pupils, designers and policy makers to} provide pupils with the opportunity to influence the design of their new school buildings

This section of the paper now addresses the impact that the study had on the pupils' ability to identify and communicate design requirements for their new school buildings and how the selected engagement mechanisms contributed to this.

When asking pupils about the engagement activities the tour around an existing low energy building was frequently referred to and nearly $100 \%$ of the pupils found it to be a rewarding experience. The tour allowed the pupils to see a low energy building in use, the building's role in helping the environment and the considered design elements to make it low energy such as daylight, thermal comfort, natural ventilation and water saving devices. This enabled the pupils to think about low energy building design during the design process of their own school buildings. As a result many of the pupils communicated that they would like their school buildings to incorporate low-energy design elements with $86 \%$ of pupils requesting natural ventilation and $90 \%$ wishing for a school with lots of natural daylight.

The engagement events provided the pupils not only with the knowledge and awareness to communicate their ideas to designers but also with the assurance that the designers would like to hear what they had to say. $93 \%$ of pupils confirmed that they would like to participate in the 
decision-making process surrounding their school design and 53\% were confident that they had the skills to be able to contribute to the process. Additionally, $73 \%$ of pupils were positive in thinking that decision makers would welcome their participation.

The study was successful in facilitating meetings between school pupils, teachers and governors and decision-makers such as designers and local council members. During the meetings pupils effectively communicated an understanding of different design elements which could contribute to a low-energy building. Comments from the pupils surrounding energy use in their new school buildings included statements such as: 'saving energy by using the sun's energy', 'saving energy by using less electricity', 'switch off lights' and 'not that many buildings have energy saving equipment in them'.

One particular requirement concerned the use of day light in the school. Pupils suggested that the school buildings should 'use less artificial light and use more daylight' and that they should also be 'facing the right way with lots of windows for bright rooms and no dark spaces'.

When asked by designers what they meant by sustainable building design the pupils used phrases such as: 'buildings that are durable', 'where it saves energy, and they included examples such as 'plant roofs', 'hard-wearing materials' and 'solar panels'. The pupils also identified the importance of water saving in buildings through 'using less water', 'using rainwater to flush toilets' and 'having push taps to save water'.

In total $60 \%$ of pupils agreed that they knew what different methods architects use to design low energy buildings and all the pupils agreed that the BSF project had increased their awareness of energy and sustainable issues. Additionally, $58 \%$ of pupils stated that they found the subjects of science and engineering interesting and would consider it as a future career. 


\subsection{The Completed School Buildings}

Since undertaking the engagement project the 4 schools within the study have been designed and constructed. Three of the schools were new builds and achieved a BREEAM 'Excellent' rating and 1 school was refurbished and achieved a BREEAM 'Very Good' rating.

Although the schools are far from achieving 'carbon neutral' they do encompass a number of the requirements that were communicated by the pupils within the study. The significant use of natural daylight is noticeable in all of the schools, with particular use in communal areas such as stair wells and dinning rooms. Additionally, all the schools have acknowledged the orientation of the buildings within the school sites, so as to make the most of solar gain within class rooms. All schools have been built to high thermal insulation standards; in excess of building regulation requirements. Natural ventilation has been used in all schools to a certain degree; however the use of air conditioning is still present within ICT, Server rooms and even some offices. Disappointingly, there is a lack of renewable energy such as solar panels or wind turbines within the schools and additionally there are no "plant roofs" as requested by several of the pupils.

\section{Conclusions}

A study of literature suggested that pupils should be engaged in the development of their new school buildings to enable improved school design, better standards of teaching and learning and improved education in science and sustainable development. Following the development of a programme of engagement, the research was successful in providing multiple engagement events for 102 pupils, aged between ten and fourteen, from four secondary schools in Leicester City. 
This research was successful in increasing pupil's awareness, knowledge and understanding of the science and engineering of low-energy schools. All the pupils taking part in the study agreed that the activities had increased their awareness of issues related to climate change and sustainable development. Additionally pupils stated that since the activities began they had contributed more frequently to conversations surrounding sustainability issues with parents, teachers and school governors in particular.

The research enabled pupils to engage in detailed discussions with the designers and architects of their new schools. The pupils presented their ideas for increased levels of thermal insulation and natural daylight, the acknowledgement of site orientation to maximise solar gain and their wish for natural ventilation. These features can now be seen in the new school buildings and additionally the pupils now have the confidence to present their ideas to professionals and are assured that those ideas will be acknowledged. For several pupils the research also reinforced the appeal of science and engineering. 58\% of the pupils either 'agreed' or 'strongly agreed' that, following the engagement events, they found science and engineering interesting.

The Sustainable Development Commission suggests that since young people have the greatest stake in the future, it is our responsibility to empower them to look after the planet in adulthood and, crucially, to question and challenge the practices of present-day decision-makers (SDC, 2009). Young people were provided with the awareness and capacity to discuss the merits of providing energy efficient technologies and design in the building of new schools. The use of a range of activities, including site visits and workshops, allowed the young people to gain valuable knowledge and understanding which were shown to have improved their capacity to engage with decision makers, designers and engineers. 
The success of the study, in raising awareness of sustainable development, can largely be attributed to the use of non-formal learning. Taking students out of their familiar learning environment and into an inspirational and exciting low-energy building allowed them to have fun whilst also learning some valuable lessons about sustainable development. Learning outside the classroom, developments in the 'informal education sector' and the outreach activities of universities and industry are a major way of widening and improving the understanding of science (Bell, 2008).

Engaging pupils in the design of their new school buildings is an excellent opportunity to introduce ESD at an early age. Not only are they learning about sustainable design and behaviour first hand but they are engaging in a process which will create a low-energy building from which

they, and future pupils, can continue to learn from for generations to come. Subsequently, the BSF process is successfully coupling two time spans of long term visions for the future and short term actions. Low-energy buildings are good examples of tools through which to teach people of all ages about sustainable development and inspiring and innovative design options.

\section{Lessons Learnt and Future Work}

The new coalition government has recently announced cuts in the BSF programme, but the scheme in Leicester is still going ahead. This work is now continuing with the 12 remaining Leicester City secondary schools, which are to be re-modelled and re-built. The successful engagement activities, presented in this paper, are being improved to continue to raise pupils' awareness and understanding of climate change and sustainable development. 
It is suggested that to teach effectively educators need to be comfortable with what they are teaching and have a sound understanding of the subject matter (Bell, 2008). Literature, and research undertaken within this study, suggests that knowledge surrounding sustainable development is inconsistent and the level of teacher knowledge surrounding the subject matter is unclear. Subsequently, future research needs to concern techniques to provide teachers, across curriculum subjects, with adequate knowledge and understanding of how ESD can effectively be incorporated into day to day lessons. This will be a first step to ensuring that ESD is considered to be part of the National Curriculum in all subjects, as opposed to being a one off event or add on. Consequently, teacher training in ESD is being considered as a significant part of the follow on project.

Although it would not be impossible to engage with all pupils across the 12 second phase schools it is important that as many pupils as possible are involved in the building and refurbishment projects and have the opportunity to increase their knowledge and understanding as a consequence. The next project shall therefore aim to disseminate information and knowledge as widely as possible within each of the schools. This will be done through school assemblies, radio and newsletters and by working closely with teachers to incorporate engagement activities into everyday lessons.

Since everyone involved in sustainable building design is on a steep learning curve, it is crucial that knowledge is captured from post-occupancy evaluations for new waves of BSF (Wilkinson, 2008). Building Management Systems (BMS), do not always perform effectively. Some reports suggest that unnecessarily complicated 'green features' can hamper teachers from getting on with teaching and in some cases causing schools to use much more energy than ones built 10, 20 and even 100 years ago (O'Reilly, 2009). Future research is required to conduct post 
occupancy evaluations of new BSF schools, including operational efficiency, effective commissioning and occupancy behavior. This is essential to provide following phases of BSF with insight into the realistic operation of low-energy school buildings. Current research, in this area, within the Institute of Energy and Sustainable Development (IESD) focuses specifically on the development of methods and techniques for the post occupancy evaluation of school buildings.

Since the completion of the $1^{\text {st }}$ phase BSF schools, Leicester City Council (LCC) has focused significantly on the challenge of designing and constructing low-energy schools. A scrutiny committee was erected to specifically overview and scrutinize the 4 completed schools. The subsequent report concluded that higher environmental standards were required within subsequent BSF phases in Leicester City. Additionally, the report suggested that all schools in Leicester City are to be 'carbon neutral' by 2013; three years earlier than national targets. IESD is working closely with LCC to ensure that the next phase of schools achieves significantly higher levels of energy efficiency.

\section{Acknowledgements}

The authors would like to thanks the kind head teachers of the four schools that took part in the research; David Powell, Liz Logie, Mel Berry and Bill Morris.

We would also like to thank the designers and architects from Miller Construction and also Leicester City Council for the part they played in this research. 


\section{References}

Bell, D. 2008. Engaging teachers, engaging pupils, engaging science: are we learning our lessons? The Association for Science Education.

Bentley, T., Fairley, C. Wright, S. 2001. Designing for Learning. Demos, London, UK Department for Children, Schools and Families. 2008. Brighter Futures - Greener Lives: Sustainable development action plan 2008 - 2010. DCSF Publications, Nottingham, UK. Department for Education and Skills (2006). Sustainable schools for pupils, communities and the environment. DfES Report.

Devine Wright, P., Devine Wright, H., Fleming, P. 2004. Situational Influences on children's beliefs about global warming and energy. Environmental Education Research. V10, No 4.

pp.123-133

Durán-Narucki. 2008. School building condition, school attendance, and academic achievement in New York City public schools: A mediation model. Journal of Environmental Psychology, Vol 28, No 3, PP. $278-286$

House of Commons Education and Skills Committee Report (2006/7). Creative Partnerships and the Curriculum. London: The Stationary Office Limited.

Jackson, L. 2007. Leading Sustainable Schools. National College for School Leadership.

Johnson, D., Maruyama, G., Johnson, R., Nelson, D., Skon, L. 1981. Effects of cooperative, competitive and individualistic goal structures on achievement: A meta-analysis. Psychological Bulletin, 89(1), 47-62.

Leicester Miller Education Compeny (LMEC) 2009. http://www.leicestermiller.co.uk/. Accessed on $5^{\text {th }}$ August 2010.

National Curriculum in Action (2009) http://curriculum.qca.org.uk/key-stages-3-and-

4/subjects/key-stage-3/science/planning-and-assessment/index.aspx. accessed 5th August 2010. 
Ofsted. May 2008. Schools and Sustainability: A climate for Change? London, UK

Olson, S., Kellum, S. 2003. The Impact of Sustainable Buildings on Educational Achievements in K-12 Schools. Leonardo Academy Cleaner and Greener Program Report, November 2003.

O’Reilly, M. 2009. Costing the Earth. http://www.bbc.co.uk/programmes/b00gvjrv. Accessed on: 29th January 2009.

Planet Science, Science Museum and Institute of Education, University of London. 2003. Student review of the curriculum: major findings. Reports of the review available at www.planetscience.com/sciteach/review. Accessed on: 5th August 2010.

Scott, W. 2002. Education and Sustainable Development: challenges, responsibilities and frames of mind. The Trumpeter, Vol. 18, No 1, Pp. 1 - 12

Sustainable Development Commission (2009). Strategic Priorities for Sustainable Schools. SDC Report.

Symons, G. September 2008. Practise, Barriers and Enablers in ESD and EE: A Review of the Research. A Report for SEEd. Shrewsbury, UK.

Teachernet. 2009. http://www.teachernet.gov.uk/management/resourcesfinanceandbuilding/bsf/. Accessed on: 5th August 2010.

Teachernet. 2007.

http://www.teachernet.gov.uk/management/resourcesfinanceandbuilding/bsf/aboutbsf/. Accessed on: 5th August 2010.

The national Framework for Sustainable Schools. 2009.

http://www.teachernet.gov.uk/sustainableschools/framework/framework detail.cfm?id=1.

Accessed on: 5th August 2010.

The World Summit on Sustainable Development (2002) http://www.worldsummit2002.org/. Accessed on: 5th August 2010.

Uzzell, D. 2000. The psycho-spatial dimension of global environmental problems. Journal of Environmental Psychology, 20, $307-318$ 
Vaughan, E. 2009. Elementary School' http://www.wbdg.org/design/elementary.php. Accessed on: 5th August 2010. Steven Winter Associates, Inc.

Wilkinson, J. 2008. Leading sustainable school building projects. National College for School Leadership report 